Send your letters to the editor, British Dental

Journal, 64 Wimpole Street, London W1G 8YS

E-mail bdj@bda.org

Priority will be given to letters less than 500

words long. Authors must sign the letter,

which may be edited for reasons of space

\section{SHO training results}

Sir, following the findings of the Headway Survey of undergraduate teaching relating to head injuries, a consortium of charities (The Brain and Spine Foundation, The Child Brain Injury Trust [CBIT] and Headway) felt it would be appropriate to explore the induction training that new Maxillo-Facial (MFU) Senior House Officers (SHOs) receive.

A questionnaire was initially piloted with MFU lead clinicians and the feedback was that only the SHOs themselves would know what training they had had. This finding in itself was felt to be noteworthy.

Consequently, questionnaires were sent to a random sample of SHOs and lead clinicians at maxillo-facial centres in the UK. Two mailouts of the questionnaire resulted in disappointing return rates of 13.3\% for lead clinicians and $7.8 \%$ for SHOs.

Although the returned sample was not large enough to draw generalisable conclusions, there were some notable trends in the information provided. We feel that it is important to share these facts so that they can inform any debate arising from the publication of the Headway Survey in this issue's education supplement.

Key themes of the responses received were:

- Attendance at an induction programme was compulsory for many, but not all SHO posts.

- Many of the SHOs funded their own places on commercially available courses, notably 'Dentist on the Ward'.

- All centres had access to neurosurgical and ENT advice on site or by phone.

Some, but not all units have responsibility for assessing head injury in individuals with head injuries and maxillofacial/ dental injuries. Others only see patients once assessment of head injury has been undertaken by a member of another team (eg A\&tE staff).

At some centres there was a discrepancy between lead clinicians, who reported that their SHOs were not responsible for assessing head injury, and SHOs who reported that they were.

Responsibility for assessing head injury was sometimes expected after an induction course which contained no training on the:
- clinical assessment of head injury

- use of the Glasgow Coma Scale (GCS)

- application of ATLS (Advanced Trauma Life Support)

- clinical signs of potentially serious head injury.

Virtually none of the SHOs had been taught:

- criteria for CT scanning

- criteria for admission for observation

- criteria for readmission following discharge, though some discrepancies with Lead Clinicians' beliefs about the training received were apparent.

None of the SHOs had received training in the use of the Paediatric Glasgow Coma Scale or PTLS (Paediatric Trauma Life Support).

If the signs of serious head injury were covered in induction training, they tended to be inadequate, focusing on loss of consciousness, amnesia and vomiting. Other symptoms/signs eg focal signs were rarely mentioned.

Some SHOs indicated that training on head injury and ATLS would be very useful.

The SHOs were split as to whether they felt the induction courses had prepared them adequately for their role or not.

We are aware that this may not have been a representative sample, but if it were, it raises issues of a lack of compliance with the guidelines issued by the Royal College of Surgeons (RCS) of England in 2003. ${ }^{1}$ These state that the induction programme should ensure that trainees can demonstrate knowledge and competence in:

'An understanding of the principles of the primary survey of an injured patient using Advanced Trauma Life Support (ATLS) system.' and

'An understanding of the Glasgow Coma Scale and ability to carry out a simple neurological examination including the cranial nerves.'

These guidelines were in place before the publication of the National Institute of Clinical Excellence (NICE) Guidelines ${ }^{2}$ on the assessment of head injuries and consequently fall short of them. The NICE

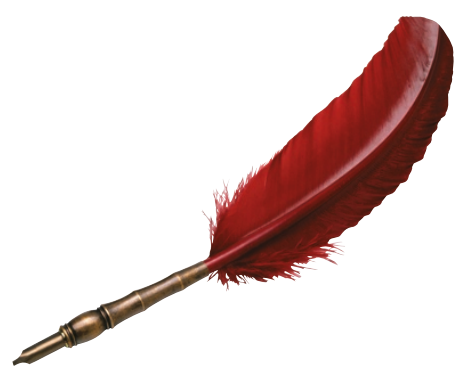

guidelines had been in place for over a year when the first questionnaires were circulated and it is disappointing that the RCS Guidelines and clinical training have not been updated to match best practice.

If teaching in relation to head injuries is improved at the undergraduate level as suggested by the Headway Survey, many of these problems should be mitigated. In the meantime, we would suggest that a review of SHO induction training is carried out promptly to ensure that the RCS and NICE guidelines are met.

We would like to state that we do not envisage maxillo-facial SHOs ever being totally responsible for the management of head injuries, but we do believe they should be capable of recognising and accurately assessing head injuries in patients seen by them initially and in those patients initially found to be non-head-injured, but who remain in the care of the maxillo-facial team.

We leave the final comment to one of the SHOs who completed the questionnaire:

'Although we usually only see patients following an initial assessment for head injury at A\&E, I still think it is important for Max-Fax SHOs to be competent in the assessment of head injuries, as patients may deteriorate, or signs/symptoms may have been missed. At the moment I think this area of education is somewhat lacking for the Max Fax SHOs.'

We would like to thank all the busy clinicians who took the time to complete the questionnaires and we hope that this is a constructive review of SHO training results.

\section{H. R. Chapman, Registered Specialist in} Paediatric Dentistry, Horsham

A. L. M. Curran, Consultant Paediatric Neurologist, Liverpool

M. Alexander, Chief Executive, The Brain \&

Spine Foundation

J. Marshall, CBIT

P. McCabe, Chief Executive, Headway

1. Lowry J. Letter to Faculty Regional Advisors et al. re SHO induction programmes, 2003.

2. National Institute of Clinical Excellence. Head Injury Triage, assessment, investigation and early management of head injury in infants, children and adults. London, 2003

doi: $10.1038 /$ sj.bdj.4812710 